\title{
Prospecção Geofísica na região de Nova Venécia e adjacências, Espírito Santo
}

Mateus de Paiva Borges, Natália Valadares de Oliveira, Luiz Gabriel Souza de Oliveira, Daniela Teixeira de Newman e José Albino Newman Fernandez, Universidade Federal do Espírito Santo/CEUNES

Copyright 2014, SBGf - Sociedade Brasileira de Geofísica

Este texto foi preparado para a apresentação no VI Simpósio Brasileiro de Geofísica, Porto Alegre, 14 a 16 de outubro de 2014. Seu conteúdo foi revisado pelo Comite Técnico do VI SimBGf, mas não necessariamente representa a opinião da SBGf ou de seus associados. E proibida a reprodução total ou parcial deste material para propósitos comerciais sem prévia autorização da SBGf.

\section{Resumo}

A área de estudo está situada na porção norte do Espírito Santo e é conhecida pela sua produção de rochas ornamentais no país. O Complexo Metamórfico Nova Venécia, de idade Paleoproterozóica, situado na zona de retroarco do Orógeno Araçuaí, representa um complexo paragnáissico de alto grau metamórfico, de rochas graníticas (tipos $S$ e I), além de rochas sedimentares e aluvionares. Devido às diversas ocorrências de mineralizações, inseridas no contexto geotectônico, foi possível investigar e destacar a ocorrência de pegmatitos, selecionando áreas-alvo potencialmente econômicas via dados aerogeofísicos magnetométricos e gamaespectrométricos, cedidos pelo Serviço Geológico do Brasil (CPRM - Projeto Aerogeofísico Espírito Santo).

\section{Introdução}

A região de Nova Venécia está localizada no extremo norte do Estado do Espírito Santo (Figura 1). Geologicamente é parte do Orógeno Araçuaí, um Sistema Orogênico Brasiliano-Panafricano que inclui os cinturões Araçuaí, W-Congo, Brasília, Ribeira, Kaoko, Dom Feliciano, Damara e Gariep (Pedrosa-Soares et al. 2001).

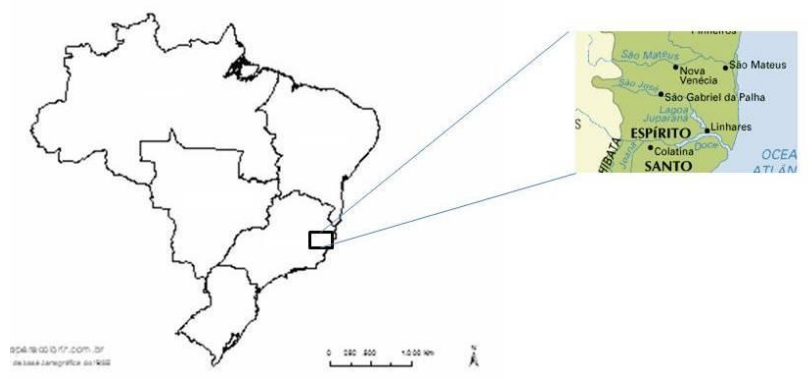

Figura 1- Mapa de localização da área de estudo.

De acordo com Baltazar et al. (2010), a região é dividida em Complexo Nova Venécia, Suítes Carlos Chagas, Ataléia, Aimorés, Grupo Barreiras e Sedimentos recentes. O Complexo Nova Venécia é representado por paragnaisses aluminosos, magmatíticos com intercalações de quartzitos e rochas calcissilicáticas, relacionados provavelmente a deposição em uma bacia de retroarco. A Suíte Carlos Chagas é constituída de granitóides megaporfiríticos foliados, peraluminosos, sincolisionais. A Suíte Ataléia constituída de tonalitos e granodioritos e leucogranitos granatíferos, foliados, Tipo $\mathrm{S}$, peraluminosos está relacionada aos eventos sincolisionais. A Suíte Intrusiva Aimorés é composta de hornblenda-biotita-granitos e hiperstênio-granitóides envolvidos ao plutonismo pós-colisional de idade cambriana. O Grupo Barreiras, de sedimentos fluviais cenozóicos e sedimentos fluviais recentes fazem parte da bacia do Espírito Santo. (Baltazar et al. 2010, TeixeiraSilva 2010).

A necessidade do conhecimento geológico/geofísico de Nova Venécia e adjacências se faz presente pelas diversas ocorrências de mineralizações e de hidrocarbonetos no Grupo Barreiras. Mapas temáticos magnetométricos e gamaespectrométricos foram gerados e interpretados, juntamente com os dados de literatura e observações feitas em campo e integrados ao mapeamento geológico visando selecionar possíveis áreas de exploração econômica na região em questão e obtenção de modelos estatísticos, utilizando-se do filtro de Fator F.

A base de dados geológicos utilizada contextualiza as folhas Mantena (SE.24-Y-A-VI) e Nova Venécia (SE.24-Y-B-IV) desenvolvida pela CPRM - Serviço Geológico do Brasil na escala de 1:100.000 via Programa Geologia do Brasil (PGB), responsável pela retomada, em larga escala, dos levantamentos geológicos básicos do país visando a ampliação acelerada do conhecimento geológico do território brasileiro, fornecendo subsídios para novos investimentos em pesquisa mineral e para a criação de novos empreendimentos mineiros.

Os dados geofísicos advêm do Projeto Aerogeofísico Espírito Santo, levantados pela CPRM Serviço Geológico do Brasil de dados magnetométricos e gamaespectrométricos nas escalas 1:100.000, 1:250.000 e 1:500.000.

\section{Metodologia/ Problema Investigado}

Com base no banco de dados cedidos pela CPRM Serviço Geológico do Brasil, foi possível processar os dados magnetométricos e gamaespectrométricos em software de domínio público, com intuito de gerar mapas temáticos (Corrigido de IGRF, Canais \% Ternário, Contagem Total e Fator F. Esses mapas são de fundamental importância para a análise de suas contribuições científicas e aferir sobre as possíveis ocorrências que compõem as rochas da região.

Para facilitar o processo de identificação geológica nos mapas temáticos, foram separados nove (9) domínios de acordo com sua litologia (Figura 2):

1) Rocha Biotita granito Tipo - I (Suíte Aimorés).

2) Rochas Charnockíticas do Tipo - I (Suíte Aimorés).

3) Rocha Biotita - granada granito (Suíte Carlos Chagas). 
4) Rochas de sedimentos fluviais arenosos.

5) Arenitos com quartzo e argilitos caolínicos (Grupo Barreiras).

6) Gnaisses com feldspato potássico e granada (Suíte Carlos Chagas).

7) Granada - biotita granito e biotita granito (Suíte Ataléia).

8) Paragnaisse e cordierita granulito (Complexo Nova Venécia).

9) Norito (Suíte Aimorés).

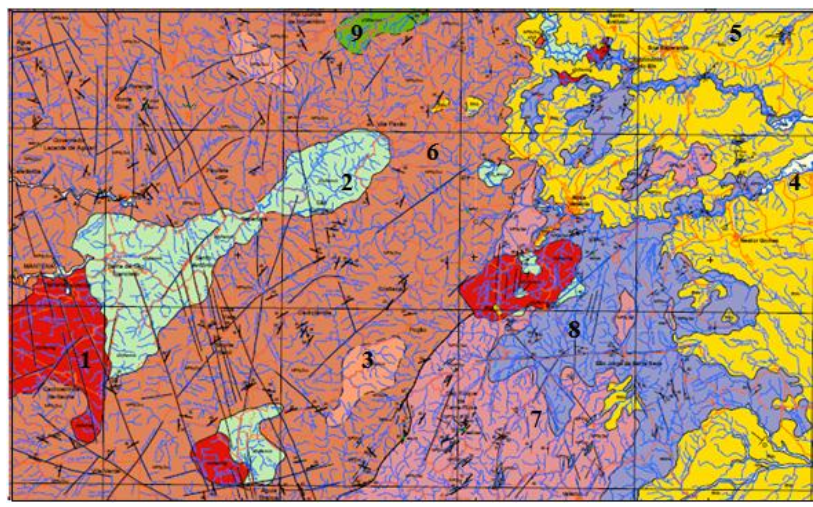

Figura 2 - Mapa geológico da Região Estudada, esta separada em domínios de acordo com sua litologia. Domínio 1: Rocha Biotita granito Tipo - I (Suíte Aimorés); Domínio 2: Rochas Charnockíticas do Tipo - I (Suíte Aimorés); Domínio 3: Rocha Biotita - granada granito (Suíte Carlos Chagas); Domínio 4: Rochas de sedimentos fluviais arenosos; Domínio 5 : Arenitos com quartzo e argilitos caolínicos (Grupo Barreiras); Domínio 6: Gnaisses com feldspato potássico e granada (Suíte Carlos Chagas); Domínio 7: Granada - biotita granito e biotita granito (Suíte Ataléia); Domínio 8: Paragnaisse e cordierita granulito (Complexo Nova Venécia); Domínio 9: Norito (Suíte Aimorés). (Fonte: CPRM, 2010).

A partir da separação dos domínios, foi possível analisar os resultados do processamento dos dados aerogeofísicos de acordo com suas características, litologia e mineralogia, sendo possível destacar áreas com possíveis mineralizações.

Devido ao conhecimento geológico precário de Nova Venécia e adjacências, saídas de campo se tornaram necessárias para possíveis elucidações e identificações de rochas, ocorrências de pegmatitos e diques. $E$, posteriormente, associações e interpretações de mapas temáticos.

\section{Resultados}

Os mapas temáticos confeccionados são: Mapa Magnetométrico (Figura 3 ), $\quad$ Mapas Gamaespectrométricos Canais \%K (Figura 4), eU (Figura 5), eTH (Figura 6), Ternário (Figura 7), Contagem Total (Figura 8) e Fator F (Figuras 9a e 9b).

A partir dos mapas, foram feitas as observações das anomalias em relação a todos os domínios antes divididos. E estas estão resumidas na tabela 1. Assim, também foi possível associar cada domínio a seus minerais principais, minerais acessórios e sua ocorrência, representado na Tabela 2.
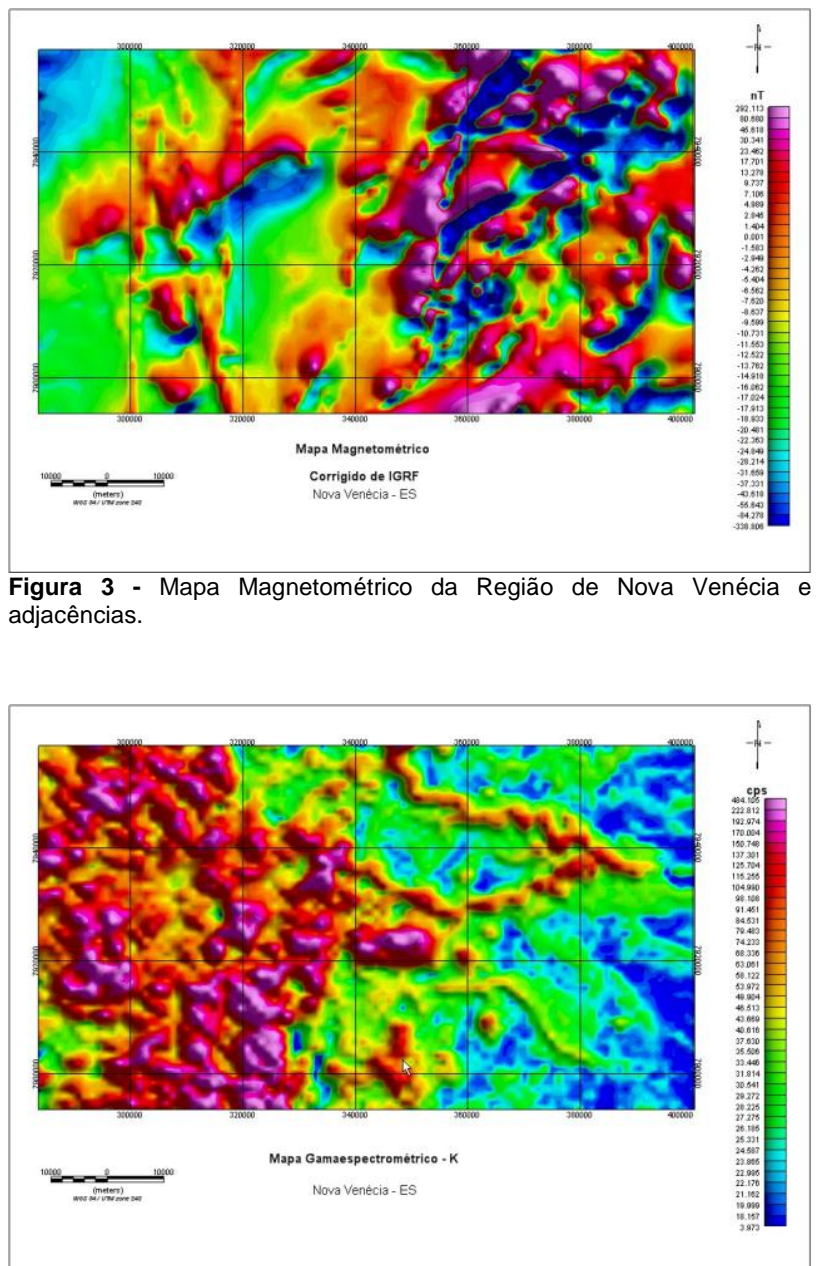

Figura 4 - Mapa Gamaespectrométrico de canal K da Região de Nova Venécia e adjacências.

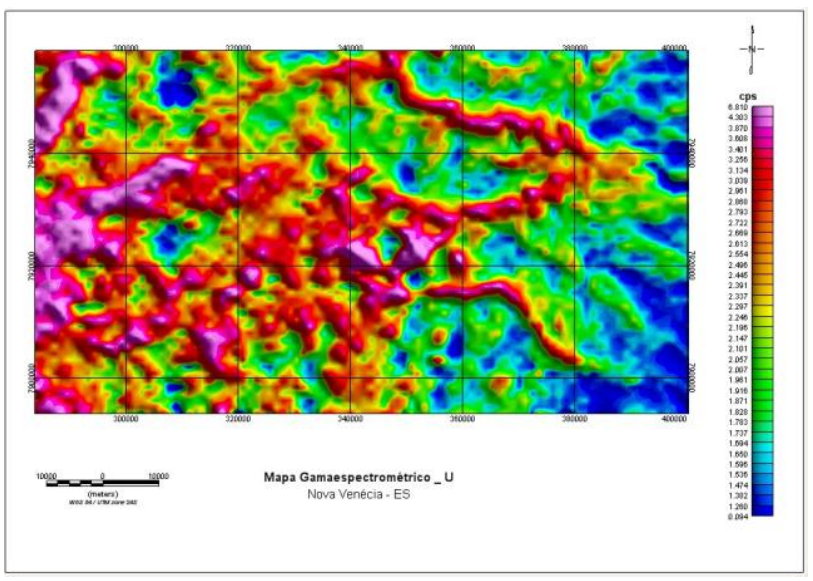

Figura 5 - Mapa Gamaespectrométrico U da Região de Nova Venécia e adjacências. 


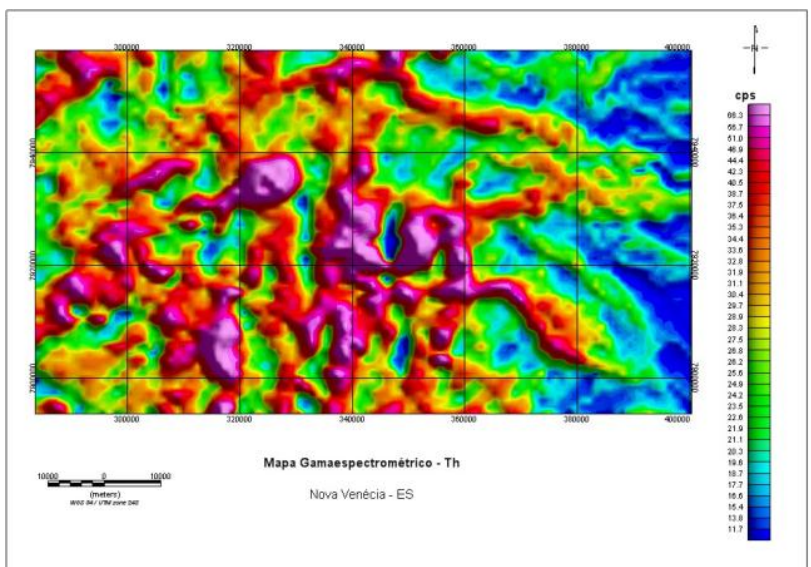

Figura 6 - Mapa Gamaespectrométrico Th da Região de Nova Venécia e adjacências.

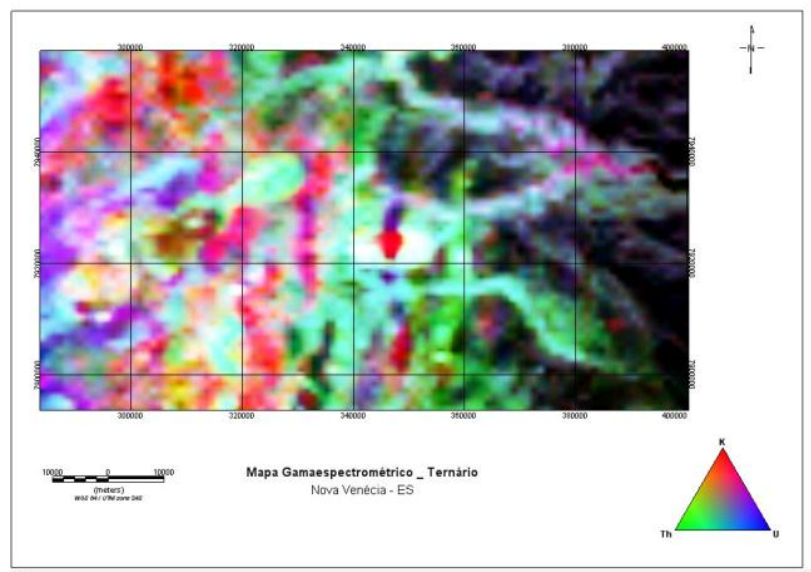

Figura 7 - Mapa Gamaespectrométrico Ternário da Região de Nova Venécia e adjacências. As porções pretas representam ausência dos elementos e as porções brancas representam a presença dos três elementos.

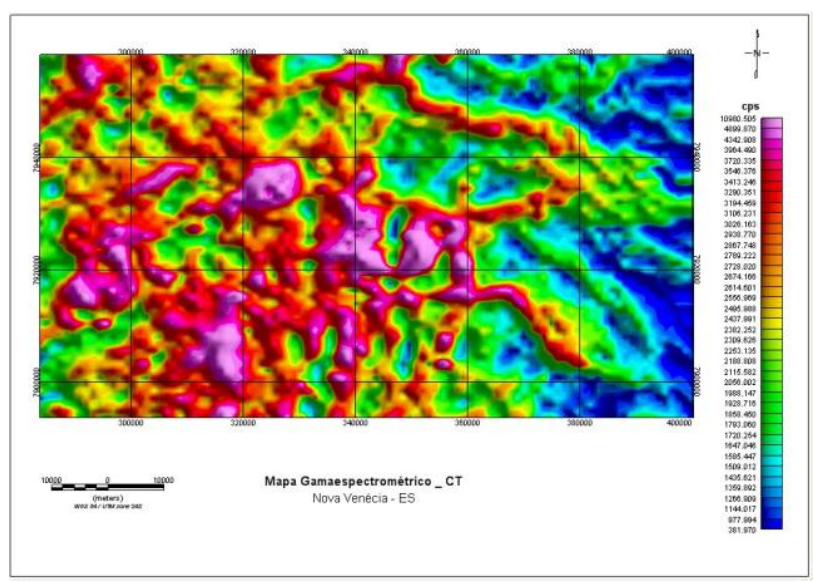

Figura 8 - Mapa Gamaespectrométrico Contagem Total da Região de Nova Venécia e adjacências.

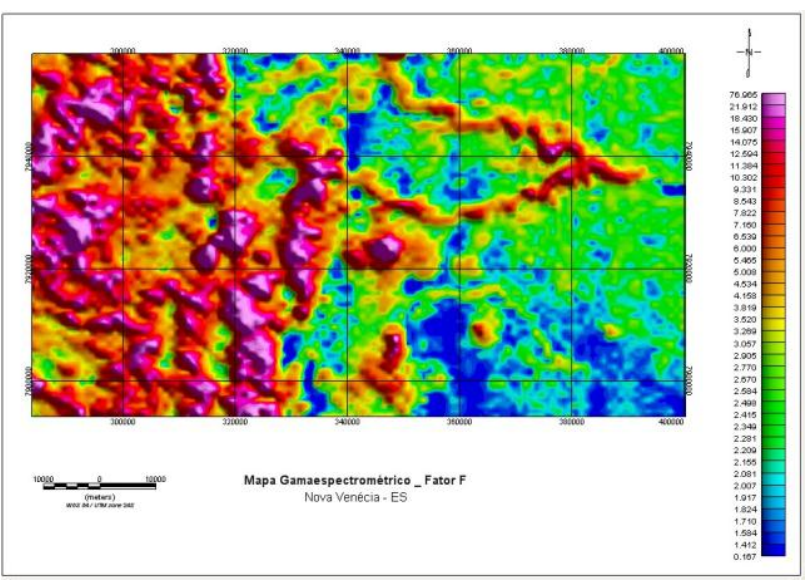

Figura 9a - Mapa Gamaespectrométrico Fator F da Região de Nova Venécia e adjacências.

Tabela 1- Relação dos Domínios com suas respectivas contribuições em cada mapa temático.

\begin{tabular}{|c|c|c|c|c|c|c|c|c|}
\hline Dominio & Rocha & Mag & $\mathrm{K}$ & Th & $\mathrm{U}$ & CT & Tem. & F.F. \\
\hline 1 & $\begin{array}{l}\text { Biotita granito Tipo -I } \\
\text { (Suite Aimorés) }\end{array}$ & \pm & $\uparrow \uparrow \uparrow$ & $\uparrow \uparrow \uparrow$ & $\uparrow \uparrow \uparrow$ & $\uparrow \uparrow \uparrow$ & $\mathrm{K}$ & \\
\hline 2 & $\begin{array}{l}\text { Chamockíticas do Tipo-I } \\
\text { (Suíte Aimorés) }\end{array}$ & - & $\uparrow \uparrow \uparrow$ & & $\uparrow \uparrow \uparrow$ & $\uparrow \uparrow \uparrow$ & $\begin{array}{l}\mathrm{K} \\
\mathrm{Th}\end{array}$ & \\
\hline 3 & $\begin{array}{l}\text { Biotita - granada granito } \\
\text { (Suite Carlos Chagas) }\end{array}$ & \pm & $\uparrow \uparrow \uparrow$ & $\uparrow \uparrow \uparrow$ & & & $\mathrm{K}$ & \\
\hline 4 & $\begin{array}{c}\text { Sedimentos fluviais } \\
\text { arenosos }\end{array}$ & - & & & & $\downarrow \uparrow$ & $\underset{\mathrm{U}}{\mathrm{Th}}$ & \\
\hline 5 & $\begin{array}{c}\text { Arenitos com quartzo e } \\
\text { argilitos caolíicos (Grupo } \\
\text { Barreiras) }\end{array}$ & \pm & $\downarrow \downarrow \downarrow$ & $\downarrow \downarrow$ & $\downarrow \downarrow \downarrow$ & $\downarrow \downarrow \downarrow$ & Th & $\downarrow \downarrow \downarrow$ \\
\hline 6 & $\begin{array}{l}\text { Gnaisses com feldspato } \\
\text { potássico e granada (Suite } \\
\text { Carlos Chagas) }\end{array}$ & \pm & & $\uparrow \uparrow \uparrow$ & & $\downarrow \uparrow$ & $\mathrm{K}$ & $\uparrow$ \\
\hline 7 & $\begin{array}{c}\begin{array}{c}\text { Granada - biotita granito e } \\
\text { biotita ganito } \\
\text { Ataléia) }\end{array} \\
\text { (Suite } \\
\end{array}$ & \pm & $\downarrow \uparrow$ & $\downarrow \uparrow$ & $\downarrow \uparrow$ & $\downarrow \uparrow$ & $\begin{array}{l}\mathrm{U} \\
\mathrm{Th}\end{array}$ & $\uparrow \uparrow \uparrow$ \\
\hline 8 & $\begin{array}{c}\text { Paragnaisse e cordierita } \\
\text { graunulito (Complexo } \\
\text { Nova Venécia) }\end{array}$ & \pm & $\downarrow \downarrow \downarrow$ & $\downarrow \downarrow \downarrow$ & $\uparrow \uparrow \uparrow$ & $\downarrow \uparrow$ & $\begin{array}{l}\mathrm{U} \\
\mathrm{K}\end{array}$ & $\uparrow \uparrow \uparrow$ \\
\hline 9 & $\begin{array}{c}\text { Norito } \\
\text { (Suíte Aimorés) }\end{array}$ & - & $\downarrow \downarrow \downarrow$ & $\downarrow \downarrow$ & $\downarrow \downarrow \downarrow$ & $\downarrow \downarrow$ & $\begin{array}{l}\mathrm{K} \\
\mathrm{Th}\end{array}$ & $\downarrow \downarrow$ \\
\hline
\end{tabular}

Tabela 2 - Domínios e seus respectivos minerais principais e acessórios e ocorrências.

\begin{tabular}{|c|c|c|c|}
\hline Dominio & Minerais Principais & Minerais Acessórios & Ocorrência \\
\hline 1 & $\begin{array}{c}\text { Feldspato potássico, Biotita e } \\
\text { quartzo }\end{array}$ & $\begin{array}{l}\text { Plagioclásio sódico, zircão, } \\
\text { apatita, sulfetos e magnetita }\end{array}$ & $\begin{array}{l}\text { Rochas igneas ácidas e } \\
\text { pegmatitos }\end{array}$ \\
\hline 2 & $\begin{array}{l}\text { Feldspato potássico verde e } \\
\text { biotita }\end{array}$ & Alguns minerais máficos & $\begin{array}{c}\text { Rochas igneas ácidas e } \\
\text { pegmatitos }\end{array}$ \\
\hline 3 & $\begin{array}{l}\text { Feldspato potássico pertitico, } \\
\text { quartzo, granada e biotita }\end{array}$ & $\begin{array}{c}\text { Sulfetos, zircão, apatita e } \\
\text { monazita }\end{array}$ & $\begin{array}{l}\text { Granitos, pegmatitos e } \\
\text { gnaisses }\end{array}$ \\
\hline 4 & Quartzo & Lama & Ambientes fluviais \\
\hline 5 & Quartzo & $\begin{array}{l}\text { Argilito caolinico } \\
\text { Silto-arenoso }\end{array}$ & Sedimentos fluviais, arenitos \\
\hline 6 & $\begin{array}{l}\text { Silimanita, granada, biotita, } \\
\text { feldspato potássico e granada }\end{array}$ & $\begin{array}{l}\text { Ocorrências de rochas: } \\
\text { Ultramilonito pobre de biotita } \\
\text { e paragnaisse }\end{array}$ & Gnaisse, pegmatitos e granitos \\
\hline 7 & $\begin{array}{l}\text { Quartzo, feldspato potássico, } \\
\text { plagioclásio sódico e biotita }\end{array}$ & $\begin{array}{l}\text { Silimanita, apatita, cordierita, } \\
\text { zircão, monazita e minerais } \\
\text { opacos }\end{array}$ & $\begin{array}{c}\text { Rochas igneas ácidas e } \\
\text { pegmatitos }\end{array}$ \\
\hline 8 & $\begin{array}{l}\text { Quartzo, plagioclásio sódico, } \\
\text { biotita, granada, cordierita, } \\
\text { silimanita e feldspato potássico }\end{array}$ & $\begin{array}{l}\text { Pirita, monazita, apatita, } \\
\text { zircão, titanita, magnetita e } \\
\text { grafita }\end{array}$ & Gnaisse, pegmatitos e granitos \\
\hline 9 & Labradorita e ortopiroxênio & $\begin{array}{l}\text { Quartzo, biotita e minerais } \\
\text { opacos }\end{array}$ & Rochas máficas e ultramáficas \\
\hline
\end{tabular}




\section{Discussão e Conclusões}

A prospecção mineral está sendo cada vez mais importante para o progresso econômico de exploração, requisitando mais pesquisas e desenvolvimento de projetos nesse setor. $\mathrm{O}$ estudo aqui apresentado mostra sua contribuição para a pesquisa de possíveis áreas onde a exploração mineral possa ser viável na região de Nova Venécia e Adjacências, no norte do Espírito Santo.

A partir de dados obtidos em campo e através da análise dos mapas temáticos a área pesquisada foi dividida em dois setores principais: $\mathrm{A}$ e $\mathrm{B}$, baseados nas diferenças observadas em relação ao Fator $F$ que auxilia na identificação de veios pegmatíticos, destacando as anomalias altas, no Setor A e anomalias baixas a intermediárias no Setor B (Figura 9b).

O Setor A engloba os domínios 1, 2, 7 e 8, que compõem as Suítes Aimorés, Ataléia e o Complexo Nova Venécia, e apresenta grandes ocorrências de granitos veios pegmatitos associados.

O Setor B engloba os domínios 3, 5, 6 e 9, que compõem a Suíte Carlos Chagas, Grupo Barreiras, e Suíte Aimorés. Apresenta ocorrência de gnaisses com feldspato potássico e granada, sendo os minerais principais o quartzo e granada. Não apresenta ocorrência significante de veios pegmatíticos.

Nos pontos visitados durante a saída de campo, inseridos no Setor A, destacam-se grandes ocorrências de pegmatitos, estes associados à alteração hidrotermal pela qual a região foi atingida. Fica evidente, a partir da análise dos resultados, que a região estudada revela grande potencial como área-alvo para exploração econômica podendo conter acumulações de minerais gemológicos e rochas ornamentais.

\section{Agradecimentos}

À CPRM - Serviço Geológico do Brasil, pela ajuda e disponibilidade dos dados aerogeofísicos do Espírito Santo.

\section{Referências}

Baltazar, O. F., Zucchetti, M., Oliveira, S. A. M. de, Scandolara, J., Silva, L. C., 2010. Folha São Gabriel da Palha e Linhares. Programa Geologia do Brasil, CPRM.

CPRM 2010. Projeto São Gabriel da Palha - Linhares Estados do Espírito Santo e Minas Gerais. Programa Geologia do Brasil.

CPRM 2010. Relatório Final do Levantamento e Processamento de Dados Magnetométricos e Gamaespectrométricos. Projeto Aerogeofísico Espírito Santo, CD-ROM.

Luiz, J. G. \& Silva, L. M. C. 1995. Geofísica de Prospecção, CEJUP. Belém, Brasil, $311 \mathrm{pp}$.
Pedrosa-Soares, A. C \& Wiedemann-Leonardos, C. M. 2000. Evolution of the Araçuaí Belt and its connection to the Ribeira Belt, Eastern Brazil. In: Cordani, U.G., Milani E.J., Thomaz Filho A., Campos D.A. (eds) Tectonic evolution of South America. Rio de Janeiro, pp.: 265-285

Pedrosa-Soares, A. C., Noce, C. M., Wiedemann, C., Pinto, C.P. 2001. The Araçuaí-West-Congo Orogen in Brazil: An overview of a confined orogen formed during Gondwanaland Assembly. Precambrian Research, 110 (1-4): 307-323.

Pedrosa-Soares A. C., Queiroga, G. N., Gradim, C. T., Roncato, J. G., Novo, T. A., Jacobsohn, T., Silva, K. L. 2006. Nota Explicativa da Folha Mantena, 1:100.000. In: Folha Mantena. Programa Geologia do Brasil, Contrato CPRM - UFMG, CD-ROM.

Queiroga, G. N., Alvim, H., Coutinho, M. O. G., Freitas, N. C., Dias, P. H. A., Pedrosa-Soares, A. C., Roncato J., Novo, T. A. 2009. Folha Nova Venécia, 1:100.000. Programa Geologia do Brasil, Contrato CPRM-UFMG, CD-ROM

Teixeira-Silva, C. M. 2010. O sistema transcorrente da porção sudeste do orógeno Araçuaí e norte da faixa. Departamento de Geologia, Universidade Federal de Ouro Preto, Tese de Doutorado, Ouro Preto, 221p. 


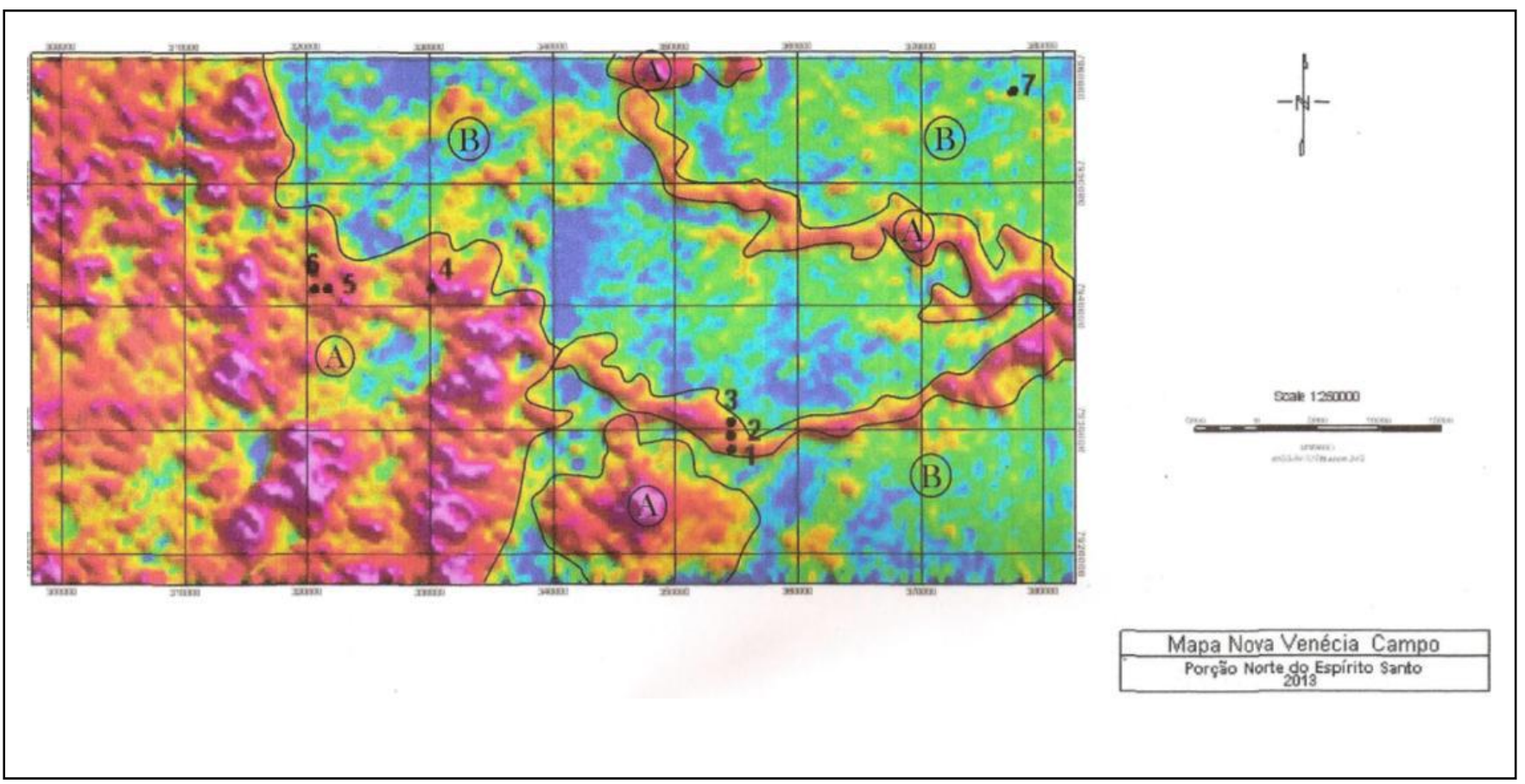

Figura 9b - Mapa Gamaespectrométrico de Fator $\mathrm{F}$ representando os Setores A e B. Os pontos 1 a 7 referem-se aos locais onde foi realizado o trabalho de campo na região investigada. 